\title{
Surgical outcome of type II odontoid fracture, Harms technique
}

\author{
Ahmed Saro ${ }^{*}$ (D), Ahmed Kamal Abdelhameid and Khaled Naser Fadl
}

\begin{abstract}
Background: Cervical trauma is a common cause of disability following spinal cord injury especially in athletic populations. The biomechanics in the atlantoaxial joint carry more than 50\% of the rotational movement which can be affected in transverse ligament tear associated with odontoid fracture type II. Odontoid fracture type II is considered an unstable fracture with a high rate of nonunion in conservative treatment. Limitation of the odontoid screws in some cases gives the chance of posterior cervical fixation to have the superior role. Use of polyaxial screws in Harms technique gives the best results in maintaining majority of the biomechanics.
\end{abstract}

Purpose: Our aim in this study is to evaluate Harms technique in patients regarding pain improvement and restoration of the motor power and to report the complications.

Study design: This is a retrospective case series study. We used the Frankel grading system to evaluate the postoperative neurological state.

Patient and methods: Between January 2015 and January 2018, 12 patients were introduced to the neurosurgical department at the Sohag University Hospital with post-traumatic type II odontoid fracture with failure of conservative treatment and not suitable for anterior odontoid screws. All patients underwent full laboratory, medical, and neurological evaluation and imaging study on the cervical spine. All patients underwent posterior cervical fixation C1-C2 by polyaxial screw Harms technique.

Results: Male ratio was predominant in our study: $75 \%$ with a mean age 34.4 years. Neck pain with limitation of the neck movement was the complaint for the all cases. Three cases came with neurological affection. Postoperative superficial infection reported in one patient; no vertebral artery or neural injuries were noticed in our study.

Conclusion: Harms technique C1-C2 fixation is a valuable choice in patients with type II odontoid fracture with failure of conservative treatment or not suitable for odontoid screw. Harms technique gives us the highest preservation of the biomechanics among the other posterior approaches.

Trial registration: NCT03768843.

Keywords: Harms technique, Odontoid fracture, Polyaxial screws, Transarticular

\section{Introduction}

The atlantoaxial $\mathrm{C} 1-\mathrm{C} 2$ joint considered an important articulation that gives about $50 \%$ of the cervical rotation around the odontoid process. Odontoid fractures are defined as a fracture at the dens of the $\mathrm{C} 2$ cervical spine. They account for $20 \%$ of all cervical spine fractures [1].

In 1974, Anderson and D'Alonzo published the most commonly accepted classification for odontoid fractures. They classified the odontoid fractures into three categories

\footnotetext{
*Correspondence: ahmedsaro33@yahoo.com

Neurosurgery Department, Sohag Faculty of Medicine, Sohag, Egypt
}

depending on the site of the fracture line. Type I is a rarely occurring fracture of the apical portion of the odontoid process. Type II is the commonest type of dens fracture. The fracture line involves the junction of the body of the dens with the body of the axis. Sometimes, type II fracture is associated with a comminuted fragment at the base of the dens called the type II A variety of fracture; this fracture is markedly unstable. Type III is a fracture extending into the body of the axis [2-4].

Type II odontoid fractures are the commonest type representing about $65-74 \%$ of the odontoid fractures. These fractures have similar biomechanical properties as 
Table 1 Frankel grading classification

\begin{tabular}{ll}
\hline Classification & Description \\
\hline A & Complete motor and sensory loss \\
B & Complete motor loss, incomplete sensory loss \\
C & Incomplete motor loss, of no practical use \\
D & Incomplete motor loss, able to ambulate with or without \\
& walking aids \\
E & No neurological symptoms or signs \\
\hline
\end{tabular}

transverse ligament injuries with loss of the translational restriction of $\mathrm{C} 1$ on $\mathrm{C} 2$, creating the potential risk for spinal cord injury and severe late craniocervical deformities when healing is not obtained [2-6].

Odontoid fracture type II is found to have high incidence of nonunion after the conservative management, especially in elderly patients (over 50 years) [5]; so, surgical treatment is recommended. Surgical strategies for treating odontoid fracture type II include direct anterior odontoid screw fixation (AOSF) and posterior cervical instrumented fusion (PCIF) each with unique indications and contraindications $[5,7]$.

In this paper, our aim is to report our experience in management of patients with odontoid fracture type II treated by a posterior $\mathrm{C} 1$ lateral mass-C2 fixation Harms technique screw road system.

\section{Material and method}

After approval of the Research Ethics Committee, 12 patients with post-traumatic odontoid fracture type II were scheduled in our Neurosurgery Department at the Sohag University Hospital for atlantoaxial fusion using polyaxial C1 lateral mass and C2 pedicle screws between January 2015 and January 2018.

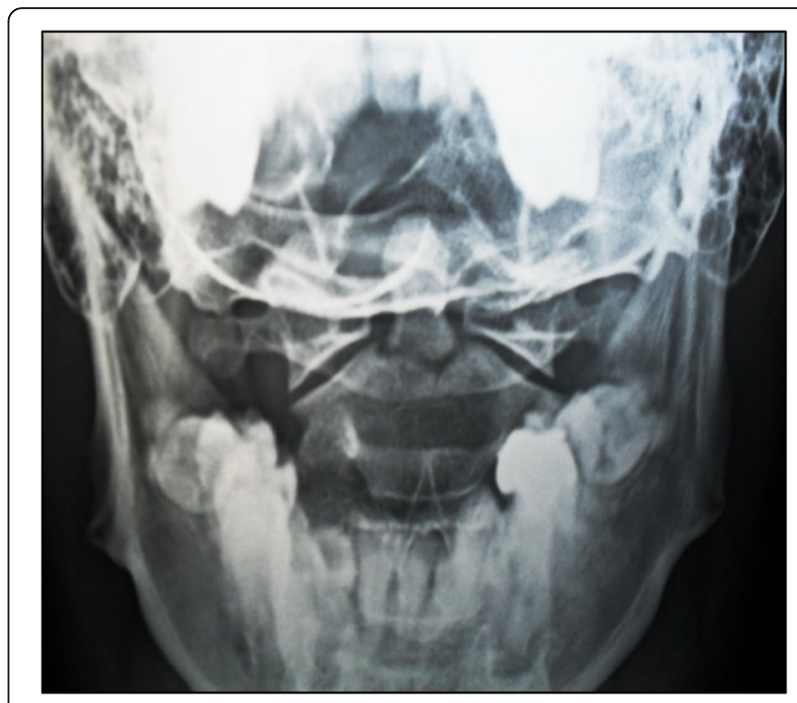

Fig. 2 X-ray shows odontoid view of odontoid fracture type II

\section{Patients included in our study are as follows:}

a) $\mathrm{C} 1-\mathrm{C} 2$ displacement that needs intraoperative reduction

b) Short neck not suitable for anterior odontoid screw

c) Osteoporotic patients

d) Odontoid fracture associated with suspected transverse ligament tear

e) Oblique line of fracture

f) Failure of union after conservative treatment

Frankel grading classification was used for all patients for a complete pre- and postoperative neurological assessment (Table 1).

Preoperative radiological assessment using cervical plain radiographs, computed tomography (CT) scan, and
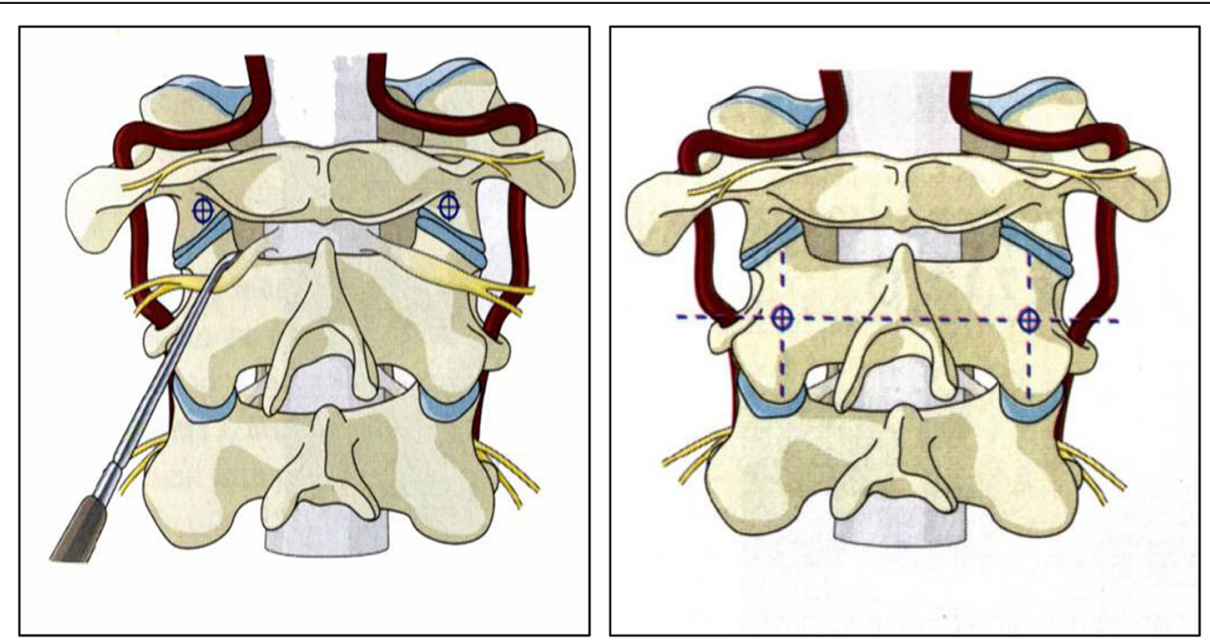

Fig. 1 Identification of the entry point of C1-C2 Harms technique 

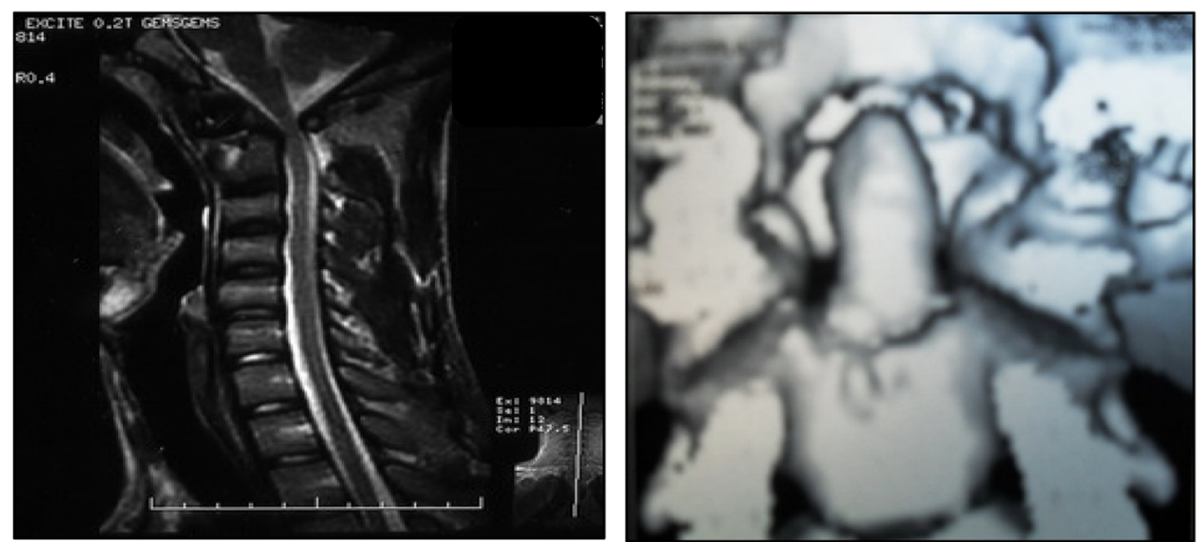

Fig. $3 \mathrm{MRI}$ cervical spine and coronal 3D CT shows odontoid fracture type II

magnetic resonance imaging (MRI) was done in all cases. Immediate postoperative cervical plain radiograph was done for all patients and then after 6 months to assess the fusion which means fusion in two subsequent vertebrae with no motion in between. Iliac bone graft was placed posterolaterally to reach fusion.

\section{Surgical technique}

Under general anesthesia with patient positioned prone using a Mayfield head holder, the neck was kept neutral with the head in the "military tuck" position. Both arms were tucked in at the sides and the shoulders retracted caudally using tape. Reduction may be performed by gentle traction, especially in acute cases. The final reduction must be confirmed using a $\mathrm{C}$-arm. This involves soft tissue release (ligaments, capsule, and scar tissues found in delayed presentation) followed by gentle manipulation. If not achieved or in more delayed cases, surgical reduction is indicated.

A skin incision was made in the midline extending from the inion to C3. Subperiosteal dissection of the paraspinal muscles was done bilaterally to expose the lateral margins of the facet joints at the $\mathrm{C} 2-3$. At $\mathrm{C} 1$, dissection was continued laterally over the posterior arch of $\mathrm{C} 1$ reaching the vertebral groove and exposing the vertebral artery.

Bleeding from the perivertebral venous plexus at this point should be controlled by hemostatic agents and bipolar diathermy. Identification and inferior mobilization of the C2 root was done to cleat the entry points of our polyaxial screw.

Exposure of the lateral mass of $\mathrm{C} 1$ and identifications of its borders was performed by a blunt micro dissector and

Table 2 Gender distribution

\begin{tabular}{lll}
\hline Gender & Male & Female \\
\hline Number & $9(75 \%)$ & $3(25 \%)$ \\
\hline
\end{tabular}

we used the medial border of the transverse foramen as it serves as our lateral limit. The entry point of the screw was identified as 3 to $5 \mathrm{~mm}$ lateral to the medial wall of the lateral mass, at the junction of the lateral mass and inferior aspect of the $\mathrm{C} 1$ arch. Trajectory should be $16^{\circ}$ medially targeting towards the anterior tubercle and $20^{\circ}$ in cephalic direction (Fig 1). C2 pars/pedicle screw entry should be achieved by identification of the upper and lower surface of the articular surface then 3-4 $\mathrm{mm}$ cephalic and laterally to the midpoint of the $\mathrm{C} 2-3$ facet line with a trajectory of $10^{\circ}$ medial and $25-30^{\circ}$ cephalic [8].

We inserted the rod, and with the rod in place, the set screws can be inserted (torque and anti-torque) to tighten the construct and fix the rod with the polyaxial screws. Posterolateral fusion should be enhanced by putting bone graft between the laminar arches. Hard collar should be held postoperatively for 6-8 weeks in osteoporotic patients to aid in neck support. Reduction can be done using a towel forceps before tightening the rod.

\section{Results}

Twelve patients with odontoid fracture type II, Figs. 2 and 3 associated with atlantoaxial instability were studied. Of

Table 3 Postoperative complications

\begin{tabular}{lll}
\hline Complication & Number & Percentage \\
\hline Vertebral artery injury & 0 & 0.0 \\
Root injury & 0 & 0.0 \\
Dural tear & 0 & 0.0 \\
CSF leak & 0 & 0.0 \\
Superficial infection & 1 & 8.3 \\
Deep infection & 0 & 0.0 \\
Screw pull out & 0 & 0.0 \\
Neurological deterioration & 0 & 0.0 \\
Nonunion & 0 & 0.0 \\
\hline
\end{tabular}


Table 4 Improvement in neurological condition using the Frankel grading system

\begin{tabular}{llll}
\hline \multicolumn{2}{l}{ Frankel grading } & Preoperative & Postoperative \\
\hline Grade A & (no function) & 0 & 0 \\
\hline Grade B & (sensory only) & 0 & 0 \\
Grade C & $\begin{array}{l}\text { (some sensory and motor } \\
\text { preservation) }\end{array}$ & 0 & 0 \\
Grade D & (useful motor function) & 3 & 0 \\
Grade E & (normal function) & 9 & 12 \\
\hline
\end{tabular}

Chi square $=3.429, p$ value $=0.489(\mathrm{NS})$

them, nine were males $(75 \%)$ and three $(25 \%)$ were females (Table 2).

The mean age at the time of surgery was $34.67 \pm$ 11.50 years (range 16-65 years). Modes of trauma were road traffic accident (83.3\%) and falling from heights $(16.7 \%)$. The main complaint with our patients was neck pain with limitation of the rotatory movement. Neurological deficit was noted in three patients and was grade D in the Frankel grading system. There was no intraoperative neural or vascular injury (Tables 3 and 4). Only surgical site infections occur in one case that improved with use of broad-spectrum antibiotics. Neck pain was regressed in all patients and assessment was performed using the Quebec scale (Table 5), while limitation of neck movement was restored regarding lateral bending in all patients with more than $80 \%$ on each side while still there was limitation of flexion-extension and axial rotation in all patients (Figs. 4, 5, 6, 7, 8 and 9).

Preoperative neurological deficit was noted in three cases $(25 \%)$ and was grade D in Frankel classification; the remaining cases were grade $\mathrm{E}$ (neurologically intact). The affected three patients showed postoperative improvement to grade $\mathrm{E}$ in the Frankel grading system (Fig 10).

Postoperative follow-up by plain cervical radiography for all patients revealed that satisfactory screw placement and reduction were achieved in all patients with no detectable hardware or implant failure. Union was obtained in all patients with an average time of 4 months.

Table 5 Assessment of pain on daily activities using the Quebec scale among our patients

\begin{tabular}{lll}
\hline Quebec scale & Preoperative & Postoperative \\
\hline Severe (98-80) & 7 & 5 \\
Moderate (40-79) & 3 & 1 \\
Mild (below 40) & 2 & 6
\end{tabular}

Paired $t$ test $=8.733, p$ value $<0.001$ (highly significant)

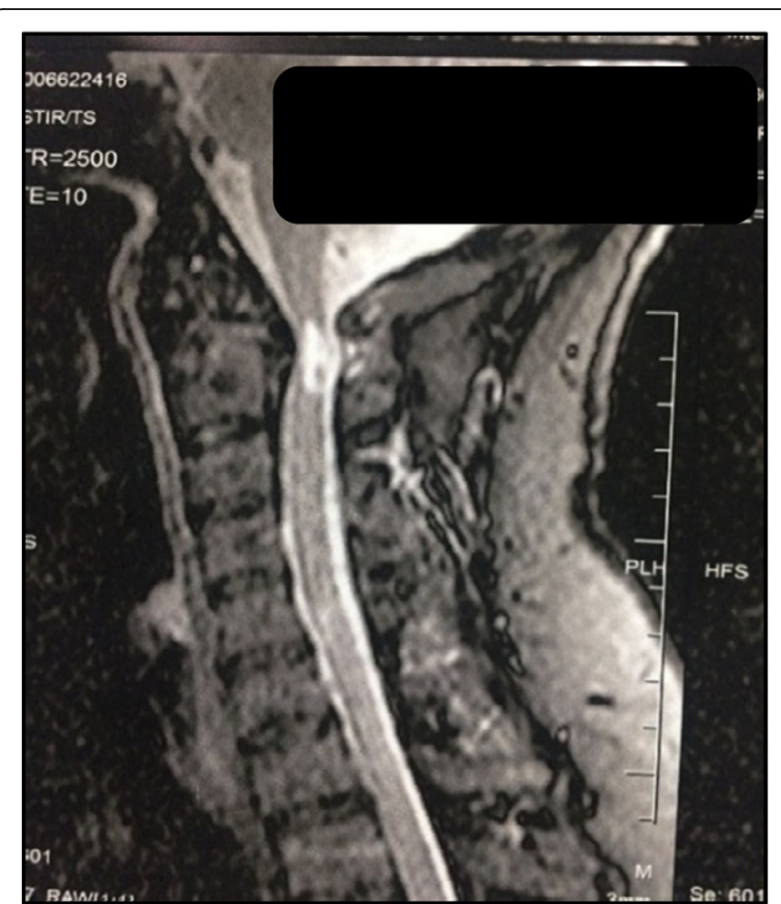

Fig. 4 Postoperative cervical spine AP and lateral views with C1-C2 fixation

\section{Discussion}

The unique anatomical articulation of the $\mathrm{C} 1-\mathrm{C} 2$ complex allows for a wide range of motion predominantly rotational motion than any other single level in the remaining cervical spine. The transverse ligament plays the main role in limitation of the translation movement at the $\mathrm{C} 1-\mathrm{C} 2$

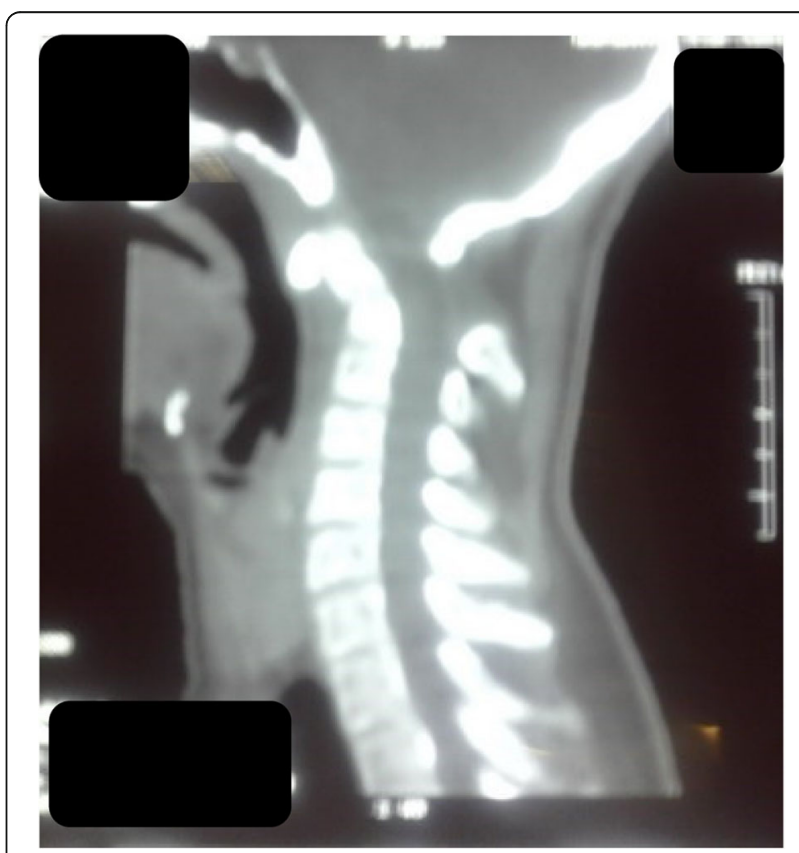

Fig. 5 Cervical CT and MRI shows odontoid fracture type II 


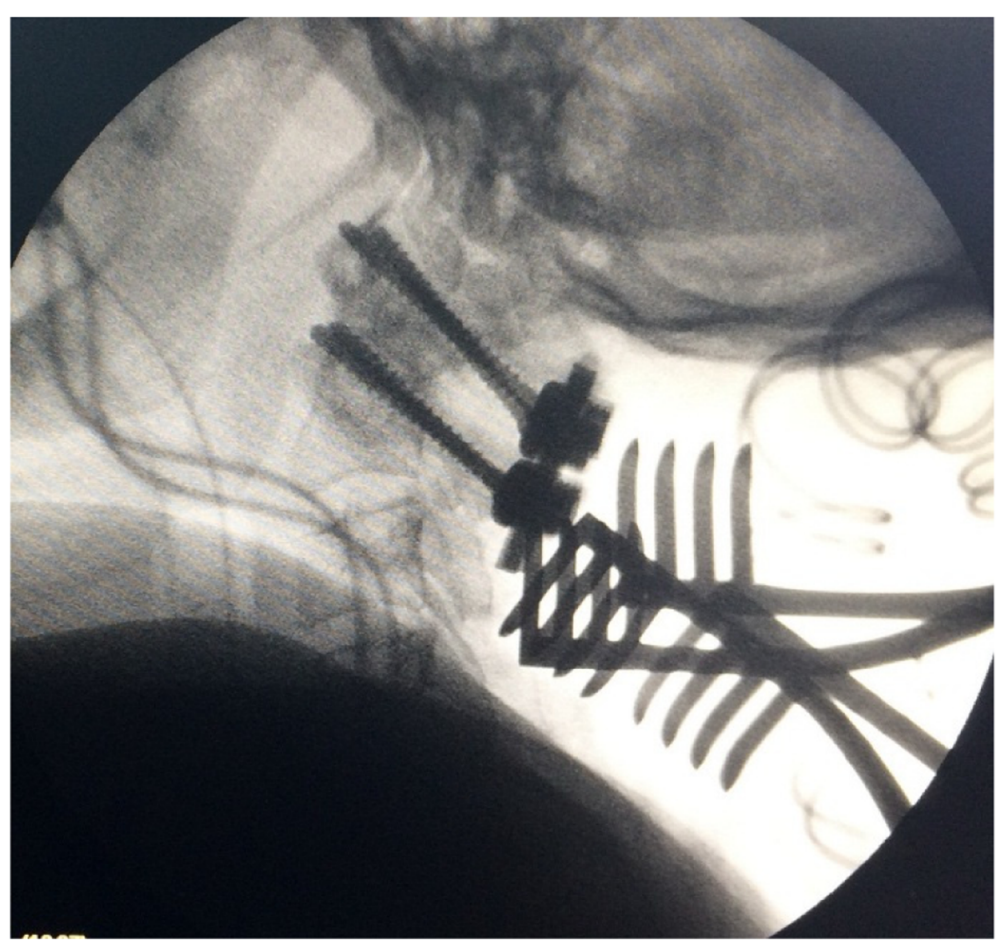

Fig. 6 Intraoperative insertion of lateral mass C1 screws and C2 pars screws under a C-arm guide

complex, which can be lost in cases of odontoid fracture type II associated with ligamentous tear causing anteroor retrolisthesis of the $\mathrm{C} 1-\mathrm{C} 2$ complex in relation to the $\mathrm{C} 2$ body with subsequent spinal cord compression producing severe neurological deficits [2].

In type II odontoid fracture, the union rate is related directly to the strategy of treatment. Conservative management with a cervical collar or halo vest has a high nonunion rate that can reach $40 \%$ [9]. Thus, surgical treatment of odontoid fracture type II has the cornerstone role for management, especially in elderly patients and those that have a higher risk for nonunion [9]. Anterior odontoid screw placement is considered as an optimum surgery in fresh cases; however, in osteoporotic patients, short neck, C1-2 displacement, and oblique line of fracture, or patients with failure of union after

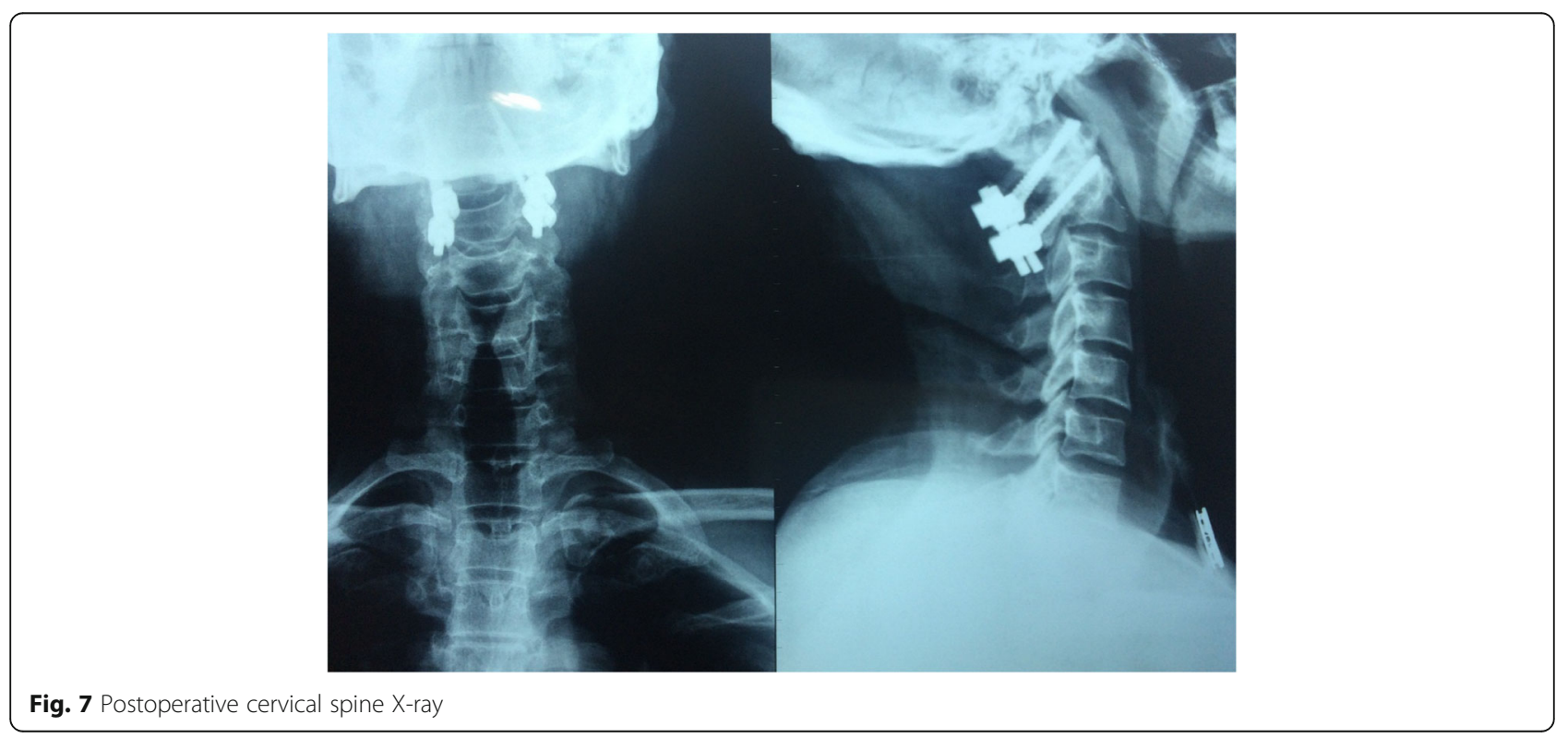




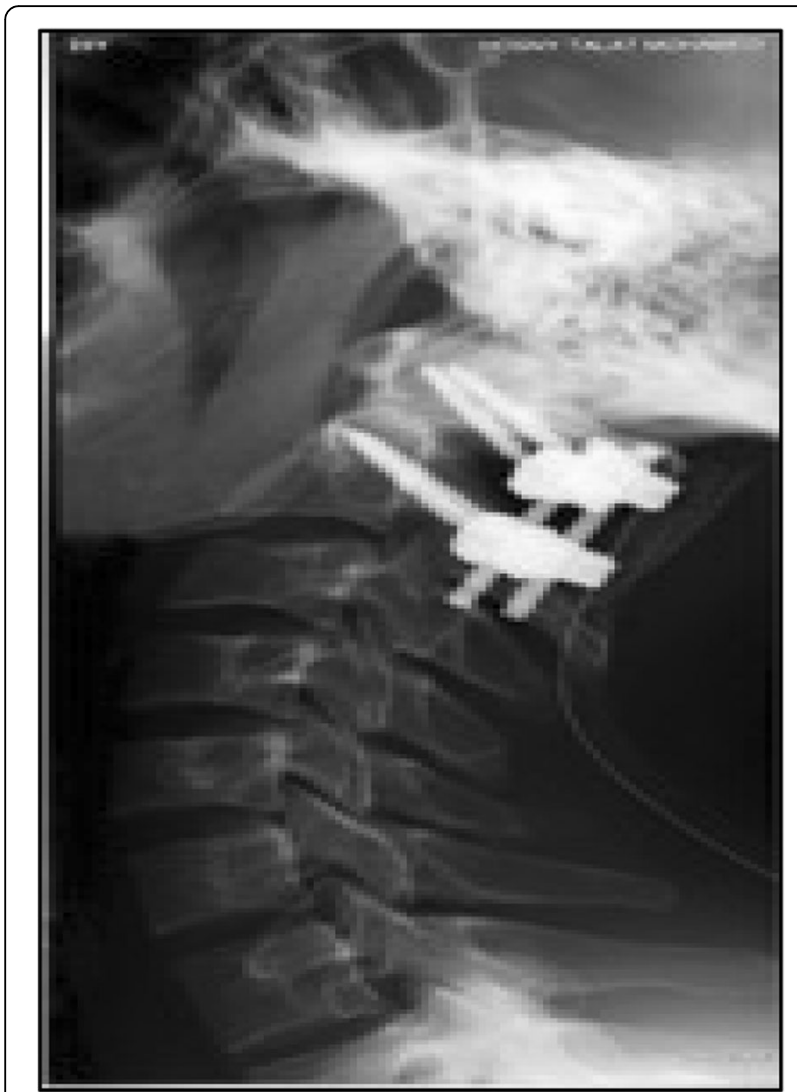

Fig. $8 \mathrm{CT}$ cervical spine shows preoperative assessment of odontoid fracture type $\|$

conservative management, posterior cervical $\mathrm{C} 1-\mathrm{C} 2$ fixation became the optimum management. Surgical treatment with posterior cervical instrumented fusion (PCIF) increases the fusion rate to more than $80 \%$ in many patient series [9].

Posterior cervical instrumented fusion (PCIF) $\mathrm{C} 1-\mathrm{C} 2$ fixation is a commonly used procedure in the management of odontoid type II fracture especially in cases associated with significant displacement of the fractured segment and avulsion of the transverse ligament and cases associated with $\mathrm{C} 1$ Jefferson fracture who are not amenable for anterior odontoid screw [10].

Different ways for a posterior approach are described. Gallie, Brooks et al., and Sonntag et al. techniques aimed to put a bone graft between the posterior arch of $\mathrm{C} 1$ and the C2 lamina with sublaminar wiring. These procedures have a satisfactory fusion rate of about $74 \%$ but there is a loss of the normal $\mathrm{C} 1-2$ rotatory motion that is responsible for $50 \%$ of the cervical spine rotation and limitation by $10 \%$ for the cervical flexion-extension movement [11-15]. Magerl in 1986 introduced a transarticular atlantoaxial screw fixation with a high biomechanical stability with superiority upon the wiring technique in the fusion rate. However, in cases associated with atlantoaxial dislocation

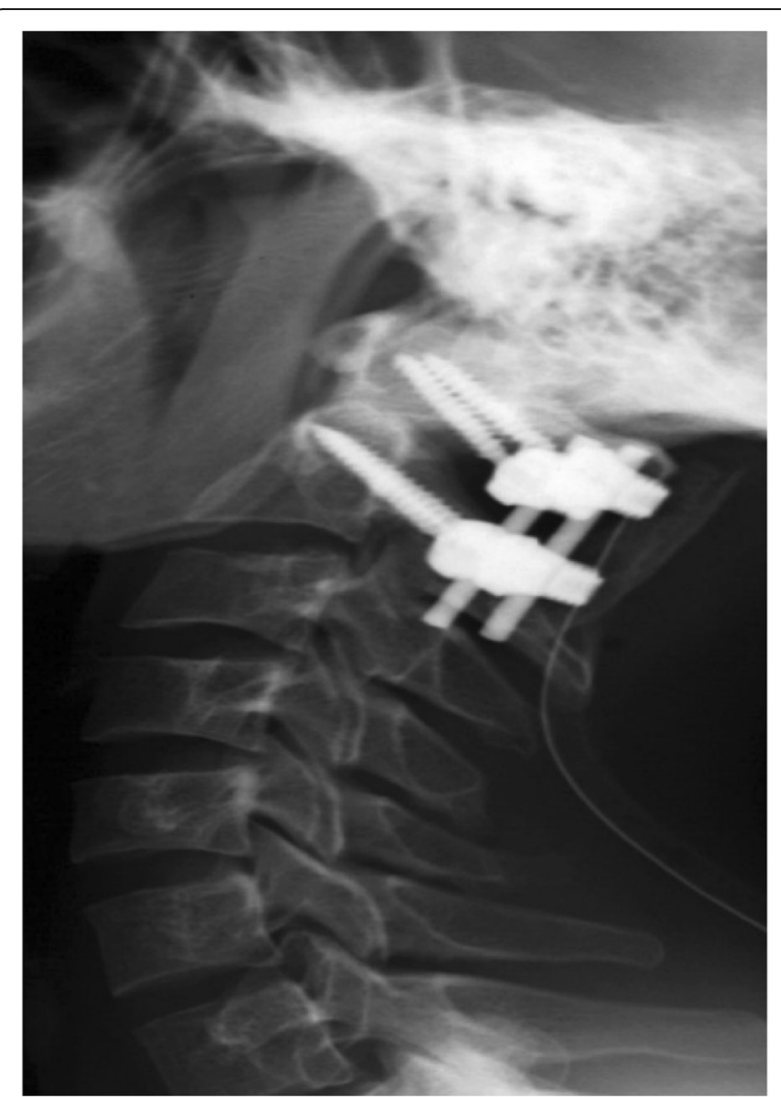

Fig. 9 X-ray cervical spine AP and lateral shows the postoperative result

or subluxation with loss of $\mathrm{C} 1-\mathrm{C} 2$ alignment, drawbacks will appear with a high difficulty of transarticular screw trajectory [16-21].

The Goel technique, in which C1-2 intraarticular spacers are used, may be performed to restore stability to a disrupted atlantoaxial complex by placing polyaxial screws and plates [22]. In 2001, Harms described a new way for atlantoaxial stabilization that could bypass the limitations found in both the previous wiring posterior fixation and the transarticular screws in cases associated with $\mathrm{C} 1-\mathrm{C} 2$ alignment loss and posterior arc involvement. Harms developed Goel's work on atlantoaxial screw fixation by a technique based on lateral mass polyaxial screw in $\mathrm{C} 1$ and pars or pedicle polyaxial screw in $\mathrm{C} 2$. This technique showed biomechanical results that are comparable to those with Magerl's technique [23, 24]. With surgeons with good expertise and well-equipped operative rooms, Harms technique shows less intraoperative complications with satisfactory postoperative biomechanics results [23].

Comparable to our results for the postoperative complications, we achieved results that were nearly achieved in previous series using the same technique. There was no injury for the neural element or the vertebral artery 


\section{Frankel Grading}

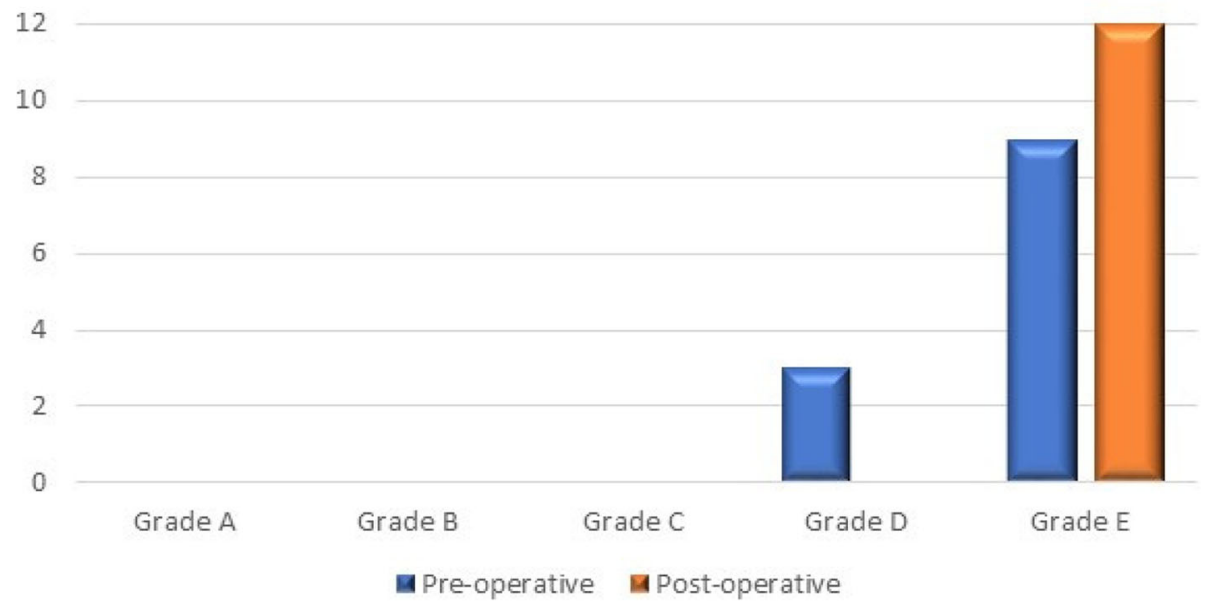

Fig. 10 Improvement in neurological condition using the Frankel grading system

among all cases; however, vertebral artery injuries were reported in $10 \%$ of literature [23-25]. Limitation in pedicle screw was reported in literature, including vertebral artery injuries especially in congenital anomalies in the course of arteries including the high right vertebral artery and we can overcome that by performing preoperative 3D angiography [24].

In 2011, Park et al. showed there were good unions for all cases in his series for $\mathrm{C} 1-\mathrm{C} 2$ posterior fixation after odontoid fracture type II. There was limitation in the rotatory movement after fixation and fusion by about $20 \%$ [26]. In our series, the limitation in the rotatory movement can reach about $17 \%$ for each side in lateral bending, thanks to a wide range allowed by the polyaxial screws. However, recent studies began to solve this issue by a temporary fixation of $\mathrm{C} 1-\mathrm{C} 2$ for 6 months then removing the screws to maintain the rotatory movement [26].

A remarkable limitation in our study is that we depended on postoperative X-ray in the evaluation of fusion which is considered not sufficient in other literature, and CT cervical spine is more accurate in the assessment of postoperative fusion [27].

\section{Conclusion}

Posterior cervical C2-C2 Harms technique fixation in the management of odontoid fracture type II gives immediate rigid fixation with biomechanics superior than that of the sublaminar wiring and transarticular screws. Intraoperative reduction can be done by manipulating the screws. Preoperative CT angiography is a mandatory investigation to rule out any abnormalities in the vertebral artery, avoiding fatal complications.

\section{Abbreviations}

C1: Atlas; C2: Axis; CT: Computed tomography; PCIF: Posterior cervical instrumented fusion

\section{Acknowledgments}

The authors would like to thank the whole members of neurosurgery department for allowing us to analyze traumatized patients data for this study.

Funding

None.

Availability of data and materials

The datasets used and/or analyzed during the current study are available from the corresponding author on reasonable request.

\section{Authors' contributions}

AKA gave the idea and collected the patients' data and postoperatively followed up the patients of the study. He also approved the submitted version. KNF is responsible for the study design, analyzed the data, and has approved the submitted version. AS meticulously revised the paper and approved the final version of the manuscript. They both have agreed to be personally accountable for their own contributions and to ensure that questions were related to the accuracy or integrity of any part of the work.

\section{Ethics approval and consent to participate}

We had approval from the local ethical committee concerning aspects of medical research. All cases included in this had signed informed written consent to participate in this research and to publish the data before being included in the study (signed by first-degree relative in non-fully conscious patients).

The ethical committee of the faculty of medicine, Sohag University, Egypt, approved this research prior to starting it, reference number 53, 2015 (reference email: emmedicine@sohag.edu.eg, reference phone number: + 2-093-4,573,124).

Consent for publication

Not applicable.

\section{Competing interests}

The authors declare that they have no competing interests.

\section{Publisher's Note}

Springer Nature remains neutral with regard to jurisdictional claims in published maps and institutional affiliations. 
Received: 29 November 2018 Accepted: 8 January 2019

Published online: 23 January 2019

\section{References}

1. White AA III, Panjabi MM. Clinical Biomechanics of the spine, 2nd ed. Philadelphia: JB Lippincott 1990; 92-97.

2. Anderson LD, D'Alonzo RT. Fractures of the odontoid process of the axis. J Bone Joint Surg Am. 1974;56:1663-74.

3. Apfelbaum RI, Lonser RR, Veres R, Casey A. Direct anterior screw fixation for recent and remote odontoid fractures. J Neurosurg. 2000;93:227-36.

4. Hadley MN, Browner CM, Liu SS, et al. New subtype of acute odontoid fracture (type II A). Neurosurgery. 1988;22:67-71.

5. Clark CR, White AAlll. Fractures of the dens. A multicenter study. J Bone Joint Surg Am. 1985;67:1340-8.

6. Müller EJ, Schwinnen I, Fischer K, Wick M, Muhr G. Nonrigid immobilization of odontoid fractures. Eur Spine J. 2003;12:522-5.

7. Denaro V, Papalia R, Di Martino A, Denaro L, Maffulli N. The best surgical treatment for type II fractures of the dens is still controversial. Clin Orthop Relat Res. 2011;469:742-50.

8. Frankel HL, Hancock DO, Hyslop G, Melzak J, Michaelis LS, Ungar GH, et al. The value of postural reduction in the initial management of closed injuries of the spine with paraplegia and tetraplegia. I. Paraplegia. 1969;7:179-92.

9. Robinson Y, Robinson AL, Olerud C. Systematic review on surgical and nonsurgical treatment of type II odontoid fractures in the elderly. Biomed Res Int. 2014;2014:231948.

10. Subach BR, Morone MA, Haid RW Jr, McLaughlin MR, Rodts GR, Comey CH. Management of acute odontoid fractures with single-screw anterior fixation. Neurosurg. 1999;45(4):812-9.

11. Apfelbaum RI. Anterior screw fixation of odontoid fractures. In: Camins MB, O'Leary PF, editors. Diseases of the cervical spine. Baltimore: Williams and Wilkins; 1992. p. 603-8.

12. Al B, Jenkins EB. Atlanto-axial arthrodesis by the wedge compression method. J Bone Joint Surg (Am). 1978;60:279-84.

13. Dickman CA, Sonntag VKH, Papadopoulos SM, Hadley MN. The interspinous method of posterior atlantoaxial arthrodesis. J Neurosurg. 1991;74:190-8.

14. Gallie WE. Fractures and dislocations of the cervical spine. Am J Surg. 1939; 46:495.

15. Julien TD, Frankel B, Traynelis VC, Ryken TC. Evidence based analysis of odontoid fracture management. Neurosurg Focus. 2000:8:1-6.

16. Grob D, Crisco JJ 3rd, Panjabi MM, Wang P, Dvorak J. Biomechanical evaluation of four different posterior atlantoaxial fixation techniques. Spine. 1992:17:480-90.

17. Magerl F, Seemann P. Stable posterior fusion of the atlas and axis by transarticular screw fixation Society C.S.R. New York: Cervical Spine, SpringerVerlag; 1986. p. 322-7.

18. Smith MD, Phillips WA, Hensinger RN. Complications of fusion to the upper cervical spine. Spine. 1991;16:702-5

19. Hajek PD, Lipka J, Hartline P, Saha S, Albright JA. Biomechanical study of C1-C2 posterior arthrodesis techniques. Spine. 1993;18:173-7.

20. Melcher RP, Puttlitz CM, Kleinstueck FS, Lotz JC, Harms J, Bradford DS Biomechanical testing of posterior atlantoaxial fixation techniques. Spine. 2002;27:2435-40.

21. Naderi S, Crawford NR, Song GS, Sonntag VK, Dickman CA. Biomechanical comparison of C1-C2 posterior fixations. Cable, graft, and screw combinations. Spine. 1998;23:1946-55.

22. Goel A, Laheri V. Plate and screw fixation for atlanto-axial subluxation. Acta Neurochir (Wien). 1994;129(1-2):47-53.

23. Harms J, Melcher Posterior RP. C1-C2 fusion with polyaxial screw and rod fixation. Spine. 2001;26:2467-71.

24. Yeom JS, Buchowski JM, Kim HJ, Chang BS, Lee CK, Riew KD. Risk of vertebral artery injury: comparison between C1-C2 transarticular and C2 pedicle screws. Spine J. 2013;13:775-85.

25. Wakao N, Takeuchi M, Nishimura M, et al. Vertebral artery variations and osseous anomaly at the C1-2 level diagnosed by 3D CT angiography in normal subjects. Neuroradiology. 2014;56:843-9.

26. Park J, Scheer JK, Lim TJ, Deviren V, Ames CP. Biomechanical analysis of Goel technique for C1-2 fusion. J Neurosurg Spine. 2011;14:639-46.

27. Koller H, Kolb K, Zenner J, et al. Study on accuracy and interobserver reliability of the assessment of odontoid fracture union using plain radiographs or CT scans. Eur Spine J. 2009;18(11):1659-68.

\section{Submit your manuscript to a SpringerOpen ${ }^{\circ}$ journal and benefit from:}

- Convenient online submission

- Rigorous peer review

- Open access: articles freely available online

- High visibility within the field

- Retaining the copyright to your article

Submit your next manuscript at $>$ springeropen.com 